\title{
Research on Energy Management Strategy of Hybrid Tramway Based on Double Fuzzy Logic Control
}

\author{
SUN Mengmeng ${ }^{1}$, YANG Jibin ${ }^{1,2}$, PENG Anjinin ${ }^{1,3}$, SONG Pengyun ${ }^{1,2,}$, ZHANG Jiye ${ }^{2}$ \\ ${ }^{1}$ College of Electrical \& Information Engineering, Southwest Minzu University, Chengdu 610225, China \\ ${ }^{2}$ State Key Laboratory of Traction Power, Southwest Jiaotong University, Chengdu 610031, China \\ ${ }^{3}$ College of Innovate \& Entrepreneurship, Southwest Minzu University, Chengdu 610225, China \\ Email: s2mpersonal@gmail.com
}

\begin{abstract}
A catenary-battery-ultracapacitor powered hybrid modern tramway is studied. The fuzzy logic controller for the catenary zone and catenary-less zone is respectively designed by analyzing the structure and operation mode of the hybrid system, then an energy management strategy based on double fuzzy logic control is proposed to enhance the fuel economy. The hybrid modern tramway simulation system is developed based on MATLAB/Simulink environment, and operation of a researching hybrid modern tramway on a planned railway line is simulated to verify the performance of the hybrid modern tramway. The simulation results demonstrate that the proposed control strategy can satisfy the demand for train dynamic performance and achieve the power distribution reasonably between the power source. Compared with the rule-based control strategy, the energy consumption of catenary traction is reduced by $12.3 \%$ and the energy recovery rate is increased by $9.3 \%$.
\end{abstract}

Keywords: Hybrid electric, tramway, energy management, double fuzzy logic control

\section{Introduction}

In recent years, environmental pollution and excessive use of energy have driven the revolution of vehicle power system worldwide. With the popularization of sustainable development, environment protection and energy conservation, the hybrid electric car came into being a research hotspot. Hybrid electric streetcar can effectively save the construction cost of urban rail transit, optimize the structure of urban public transport, reduce the damage to urban streets, and achieve more efficient and convenient urban rail transit. $[1-2,7]$.

In the past few years, Energy Storage System (ESS), which is composed of power batteries with high specific Energy and supercapacitors with high specific power, has been extensively studied and applied [1-7]. Multi-energy increases the power capacity of trains, meanwhile, increases the complexity of system operation mode and control. To achieve the switching of various working modes, improve the overall efficiency of the power supply system, and achieve the overall optimal performance of the train, reasonable energy management strategies should be adopted $[1,6,7]$. More and more researchers devote themselves to the study of energy management strategy and micro-grid of hybrid electric vehicles[6,12,14]. In recent years, scholars at home and abroad have also carried out relevant research and Application on the energy management strategy of hybrid orbital vehicles [1, 7-13]. The main purpose of energy management strategy of hybrid electric tram system is to regulate the power distribution between fuel cells and energy storage elements in the system. There are two types of energy management strategy, rule-based and optimum-based. The former makes rules according to the experience of developers, and the latter optimizes the system according to its physical characteristics. Literature [1] proposes an energy management method based on dynamic factor strategy by reducing the output energy conversion process of fuel cells. Literature [2], the fuzzy logic is applied to the main control block of the vehicle, and a pair of membership functions are used to assist the power flow controller to select the appropriate power distribution of the hybrid power transmission system in real time according to the existing resources. Literature [7] proposes a switching energy management strategy based on deterministic rules for grid/power battery/ultracapacitor hybrid trains. Literature [8-9] applied the methods of minimum equivalent fuel consumption, fuzzy control and predictive control respectively to optimize the energy management strategy of fuel cell hybrid tram. Literature [10] combines wavelet analysis method with 
fuzzy control to optimize the energy management strategy of fuel cell hybrid electric tram. Literature [13] proposes an energy management strategy based on PMP Energy Management Strategy and Braking Speed Optimization Strategy.

Energy management system has the characteristics of nonlinear, time-varying, and has many input and output structure. Meanwhile, the fuzzy control does not depend on the precise mathematical model, furthermore, with regard to the control for nonlinear and complex object the fuzzy control shows the advantages of good robustness and high control performance, as a result, the fuzzy control can be used in the energy management system, realizing the power allocation between power sources [2, 12-13]. Considering the requirements of reducing the working conditions of high current discharge mode of power battery, restraining the fluctuation of power grid and reducing traction energy consumption of power grid, we propose a double fuzzy logic control (DFLC) energy management strategy based on engineering experience. The main idea of this strategy is to design three input singles in no-grid area. The output fuzzy controller is designed with three inputs and two outputs in the network interval. Subsequently, in order to verify the effectiveness of the energy management strategy, a hybrid electric tram simulation system based on backward simulation and forward simulation is developed, and the simulation analysis is carried out using the data provided by the tram manufacturer.

\section{System Structure and Working Mode}

\subsection{System Structure}

The power system structure of the hybrid electric tram studied in this paper is shown in figure 1 . The power system is mainly composed of pantograph, power battery pack, super battery pack, bidirectional dc-dc DC converter, traction motor, dc-ac traction inverter and auxiliary converter. Trains are powered by a pantograph connected to a power grid. The power battery pack and the ultracapacitor pack are connected to the DC bus through a bi-directional dc-dc converter to provide energy for the train and recover braking energy.

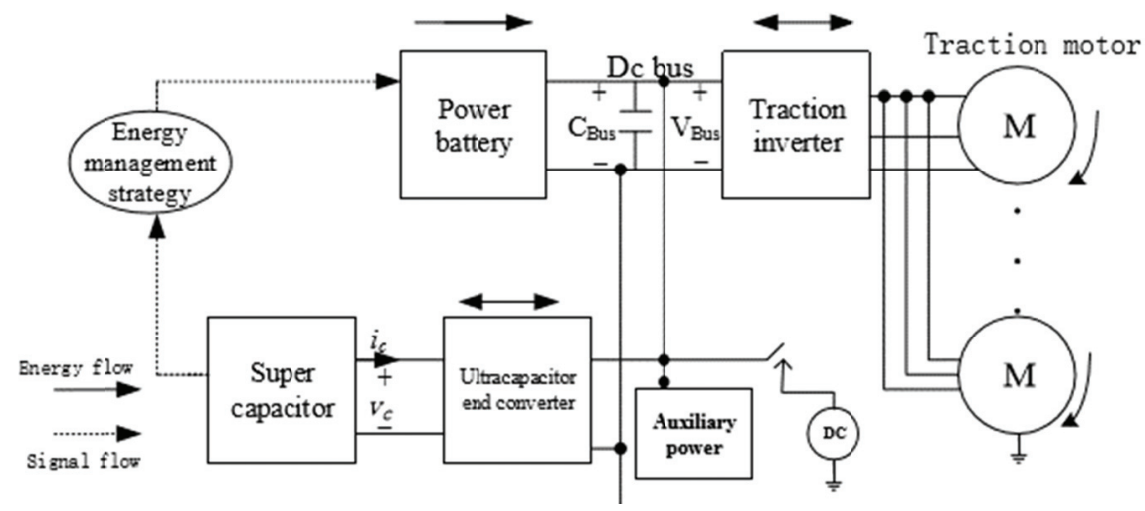

Figure 1. Hybrid system diagram

\subsection{System Working Mode}

Traditional trams use overhead catenary or the third rail as the power source, while the energy of parking braking is dissipated through the form of resistance braking and mechanical braking. When the vehicle-mounted energy storage hybrid electric tram runs without network within the interval, the energy stored by ESS provides traction energy for the train. On the contrary, when the train is running with a network, the power grid provides traction energy for the train while charging the ESS. ESS recycles a large amount of regenerative braking energy under braking conditions. The operating mode of the power system of hybrid electric tram is more complex and changeable than that of traditional tram. For the convenience of analysis, $P_{b u s}, \mathrm{~d}$ is defined, and is the required power of working condition at the dc bus end. $P_{c a t}$ is the power output of the power grid; $P_{b a t t}$ and $P_{u c}$ are the input/output power of power battery and 
ultracapacitor respectively (positive value means discharge state, negative value means charging state); $\eta_{d d}$ represents the efficiency of a dc-dc converter.

\subsubsection{Interval operation mode without power grid}

In areas without power grids, the power source of the train is ESS, and its working mode is as follows: 1) Low-power traction working mode. In this mode, the demand power of the working condition is low, with the power battery drives the train separately as the main power source, then the power balance relation in this mode is

$$
\left\{\begin{array}{c}
P_{\text {bus }, \mathrm{d}}=P_{\text {batt }} \eta_{\mathrm{dd}} \\
P_{\text {cat }}=0 \\
P_{\text {uc }}=0
\end{array}\right.
$$

2) High-power traction operation mode. In this mode, the demand power of the working condition is high, with the power battery and the supercapacitor driving the train simultaneously, then the power balance relation in this mode is

$$
\left\{\begin{array}{c}
P_{\text {bus }, \mathrm{d}}=\left(P_{\text {batt }}+P_{\mathrm{uc}}\right) \eta_{\mathrm{dd}} \\
P_{\text {cat }}=0
\end{array}\right.
$$

3) Low power regenerative braking mode. In the braking condition, the charging of the ultracapacitor is given priority, that is, the charged state (SOE) of the ultracapacitor is given priority to ensure that the peak power is provided in the next high-power traction area. In the working mode, the braking power recovered by the ultracapacitor alone is defined as the working mode of low-power regenerative braking, and the power balance relation in this mode is

$$
\left\{\begin{array}{c}
P_{\text {bus }, \mathrm{d}} \eta_{\mathrm{dd}}=P_{\mathrm{uc}} \\
P_{\text {cat }}=0 \\
P_{\text {batt }}=0
\end{array}\right.
$$

4) High power regenerative braking working mode. In this working mode, regenerative braking power is strong, and both the ultracapacitor and the power battery are charged to recover energy. The power balance relation under this mode is

$$
\left\{\begin{array}{c}
P_{\text {bus } \mathrm{d} d} \eta_{\mathrm{dd}}=P_{\text {batt }}+P_{\mathrm{uc}} \\
P_{\text {cat }}=0
\end{array}\right.
$$

\subsubsection{Grid operation mode}

The grid, power batteries and ultracapacitors all provide traction energy for the train within the grid range, and the mode of operation is as follows:

1) Single-grid traction working mode. In this mode, the SOC and SOE of the power battery are relatively high, and there is no need for charging. The power required for traction of the train is provided by the power grid. The power balance relation under this mode is

$$
\left\{\begin{array}{c}
P_{\text {bus }, \mathrm{d}}=P_{\text {cat }} \\
P_{\text {batt }}=0 \\
P_{\text {uc }}=0
\end{array}\right.
$$

2) "Grid traction + ESS charging" working mode. In this mode, the SOC or SOE of the power cell is lower than the set threshold, and the power grid can provide the traction power required while charging the ESS that needs to be charged. The power balance relation under this mode is

$$
P_{\text {cat }}=P_{\text {bus }, \mathrm{d}}+\frac{\left|P_{\text {batt }}\right|+\left|P_{\text {uc }}\right|}{\eta_{\text {dd }}}
$$

3) Regenerative braking working mode. The working mode of regenerative braking with mesh interval is the same as that without mesh interval, which is also divided into low-power regenerative braking mode 
and high-power regenerative braking mode. The power balance relationship is shown in formula (3) and formula (4) respectively.

\section{$3 \quad$ Energy Management Strategy}

The dual fuzzy controller (DFLC) as shown in figure 2 was designed based on the above analysis. During braking, braking energy is recovered by the energy storage equipment of the system. To reduce the fluctuation of the power grid, the power grid does not provide energy during braking, that is, the power distribution principle of the grid interval when braking is the same as that of the non-grid interval. The fuzzy controller is defined as "fuzzy controller 1 (FLC1)" if the required power is less than 0 in the netless interval and the netted interval. The fuzzy controller with network interval and demand power not less than 0 is "fuzzy controller 2 (FLC2)". The two controllers switch control according to whether there is a power grid. The output of FLC1 is the required output power of power battery $P_{b a t t, d}$, the required output power of ultracapacitor Puc,d is calculated by different value. The output of FLC2 is the required output power of power battery Pbatt,d and the output power of ultracapacitor Puc,d. The actual input and output of the fuzzy controller are solved by a linear transformation, and the Mamdani reasoning method is used for the inference of fuzzy relations. After fuzzy reasoning, the weighted average method (area barycenter method) is used for the clear calculation [11].

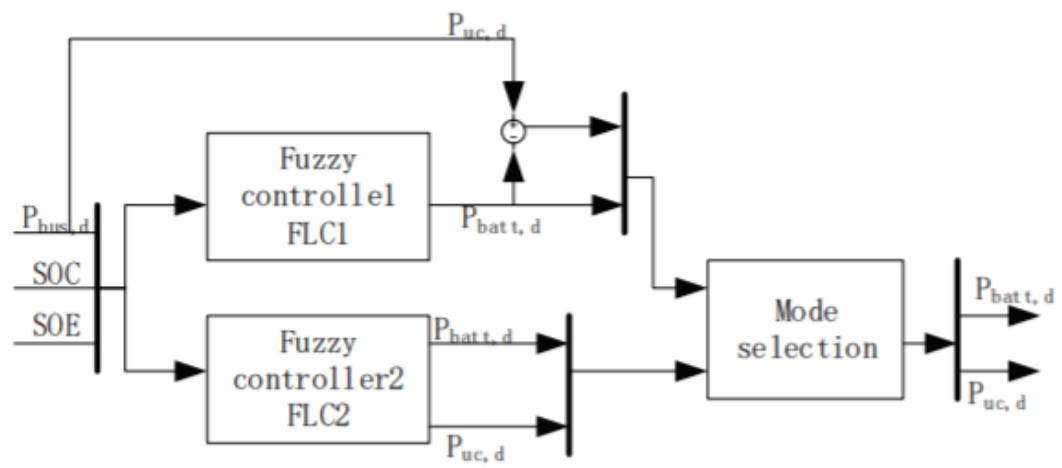

Figure 2. Hybrid power system architecture diagram.

\subsection{FLC1 Design}

Set $P_{\text {bus,d }}$ the fuzzy domain of $\mathrm{d}$ is $[-1,1], \mathrm{SOC}$ is $[0,1], \mathrm{SOE}$ is $[0,1], P_{\mathrm{batt}, \mathrm{d}}$ is $[-1,1]$. The fuzzy subset of $P_{b u s, d}$ is divided into $\{\mathrm{HB}, \mathrm{MB}, \mathrm{LB}, \mathrm{M}, \mathrm{LT}, \mathrm{MT}, \mathrm{HT}\}$, the fuzzy subset of SOC is divided into $\{\mathrm{L}, \mathrm{M}, \mathrm{H}\}$, the fuzzy subset of SOE is divided into $\{\mathrm{L}, \mathrm{M}, \mathrm{H}\}$, the fuzzy subset of $P_{\text {batt,d }}$ is divided into $\{\mathrm{HC}, \mathrm{LC}, \mathrm{M}, \mathrm{LD}$, HD\}. References [1,13], and combined with engineering experience, the membership function was designed. In order to avoid over-charging and over-discharge of power batteries and supercapacitors, the range of the fuzzy subset $\mathrm{M}$ of SOC is defined as [0.4,0.88], and the range of the fuzzy subset M of SOE is $[0.6,0.98]$. In application, considering that the charging current of power battery is small, the range of fuzzy subset $\mathrm{M}$ of $P_{\mathrm{batt}, \mathrm{d}}$ is $[-1,1]$. Figure 3 shows the membership function curves of input and output variables.

Based on the practical engineering experience, referring to the analysis of the references $[1,8,11]$, and taking the structure of the hybrid system and working mode in this paper into consideration , The design of FLC1 fuzzy control rules follows the following principles: 1) avoid ESS large current charge and discharge conditions, namely, reducing power battery or super capacitor separate work mode, increase the working mode of collaborative supply both moment; 2) in the braking condition, if both SOC and SOE are small, that is, both are within the range of fuzzy subset L and M, charging the ultracapacitor is given priority; 3) in the braking condition, when the braking power is low, the SOC is low and the SOE is high, the power battery shall be charged first. 

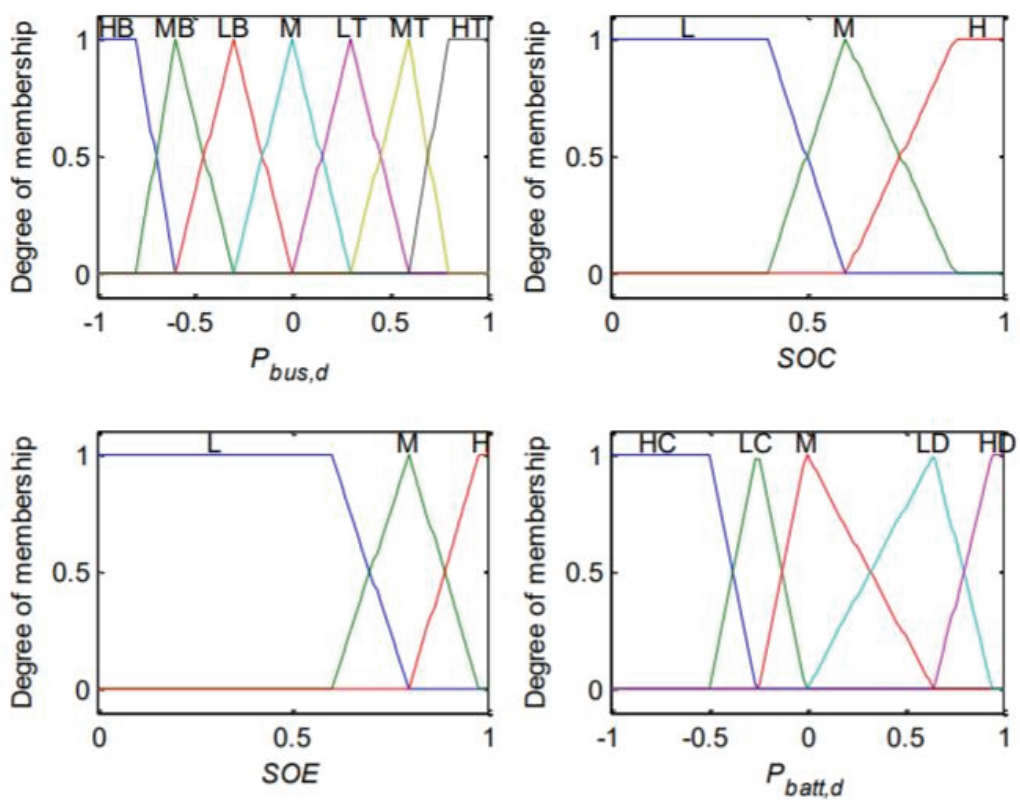

Figure 3. Membership functions of input and output variables for No.1 FLC.

According to the above analysis, the rules of FLC1 fuzzy inference are shown in table 1 . The form of fuzzy inference is: "If $P_{\text {bus,d }}$ is Ai and $\mathrm{SOC}$ is $\mathrm{Bi}$ and $\mathrm{SOE}$ is Ci, then $P_{\text {batt,d }}$ is $\mathrm{Di}, P_{\mathrm{ucc}, \mathrm{d}}$ is Ei".

Table 1. The fuzzy reasoning rules for No.1 FLC.

\begin{tabular}{ccccccccc}
\hline \multicolumn{1}{c}{$S O E=L$} & \multicolumn{7}{c}{$P_{b u s, d}$} \\
\cline { 2 - 8 } & & $H$ & $M$ & $L$ & $M$ & $L$ & $M$ & $H$ \\
\hline SOC & $L$ & $H$ & $H$ & $L$ & $M$ & $L$ & $L$ & $L$ \\
& $M$ & $H$ & $L$ & $M$ & $M$ & $L$ & $H$ & $H$ \\
& $H$ & $L$ & $L$ & $M$ & $M$ & $L$ & $H$ & $H$ \\
\hline \multirow{2}{*}{$S O E=M$} & \multicolumn{7}{c}{$P_{b u s, d}$} \\
\cline { 2 - 8 } & $H$ & $M$ & $L$ & $M$ & $L$ & $M$ & $H$ \\
\hline SOC & $L$ & $H$ & $H$ & $M$ & $M$ & $M$ & $L$ & $L$ \\
& $M$ & $H$ & $L$ & $M$ & $M$ & $L$ & $L$ & $H$ \\
& $H$ & $L$ & $L$ & $M$ & $M$ & $L$ & $H$ & $H$ \\
\hline \multirow{2}{*}{$S O E=H$} & & & & $P b u s, d$ & & & \\
& & $H$ & $M$ & $L$ & $M$ & $L$ & $M$ & $H$ \\
$S O C$ & $L$ & $H$ & $H$ & $L$ & $M$ & $M$ & $M$ & $M$ \\
& $M$ & $H$ & $H$ & $L$ & $M$ & $L$ & $L$ & $L$ \\
& $H$ & $L$ & $L$ & $L$ & $M$ & $L$ & $L$ & $H$ \\
\hline
\end{tabular}

\section{$3.2 \quad$ FLC2 Design}

Since in FLC2 , only the power distribution under the condition required power not less than 0 is processed, the fuzzy domain scope of $P_{\text {bus }}$ is $[0,1]$, and the fuzzy subset is divided into $\{\mathrm{LT}, \mathrm{MT}, \mathrm{HT}\}$. The fuzzy subsets of the input variables SOC and SOE are the same as those of FLC1. In the grid area, to precisely control the input and output of the supercapacitor, FLC2 increases the output variable, and its with fuzzy domain scope [-1,1], and the fuzzy subset is divided into $\{\mathrm{HC}, \mathrm{LC}, \mathrm{M}, \mathrm{LD}, \mathrm{HD}\}$. The membership function of SOC and SOE in FLC2 is the same as that of FLC1, as shown in figure 3. The membership function design of input variables is shown in figure 4(a), and the membership function of the added output variables is shown in figure $4(\mathrm{~b})$. 

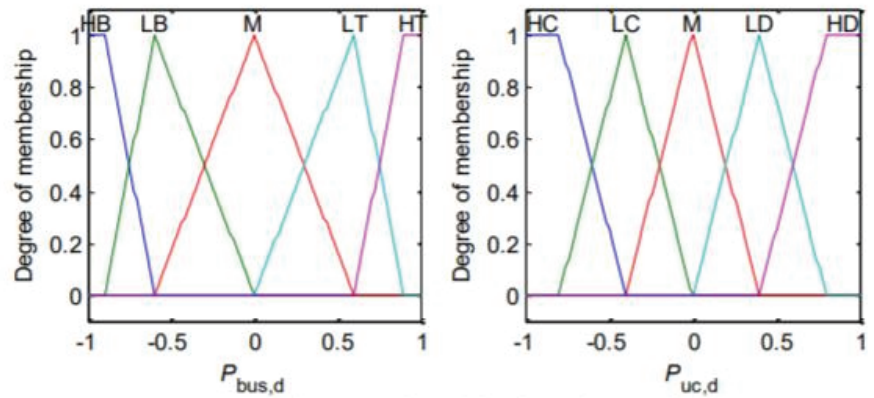

Figure 4. Membership functions of input and output variables for No.2 FLC

Table 2. The fuzzy reasoning rules of Pbatt,d for No.2 FLC

\begin{tabular}{lcccc}
\hline SOE $=L$ & & \multicolumn{3}{c}{$P_{\text {bus }, d}$} \\
\cline { 3 - 5 } & & $L T$ & $M T$ & $H$ \\
\hline SOC & $L$ & $H$ & $H C$ & $L$ \\
& $M$ & $H$ & $H C$ & $M$ \\
& $H$ & $L$ & $L C$ & $M$ \\
\hline$S O E=M$ & & \multicolumn{3}{c}{$P_{\text {bus }, d}$} \\
\cline { 3 - 5 } & $L$ & $H$ & $M T$ & $H$ \\
\hline SOC & $M$ & $H$ & $H C$ & $M$ \\
& $H$ & $L$ & $L C$ & $M$ \\
\hline SOE $=H$ & & & $P_{\text {bus }, d}$ & \\
\cline { 3 - 5 } & & $L T$ & $M T$ & $H$ \\
\hline SOC & $L$ & $H$ & $H C$ & $M$ \\
& $M$ & $H$ & $L C$ & $M$ \\
& $H$ & $L$ & $L C$ & $M$ \\
\hline
\end{tabular}

Table 3. The fuzzy reasoning rules of Puc,d for No.2 FLC

\begin{tabular}{lcccc}
\hline SOE $=L$ & & \multicolumn{3}{c}{$P_{\text {bus }, d}$} \\
\cline { 3 - 5 } & & $L T$ & $M T$ & $H$ \\
\hline SOC & $L$ & $H$ & $L C$ & $M$ \\
& $M$ & $H$ & $L C$ & $M$ \\
& $H$ & $H$ & $L C$ & $M$ \\
\hline SOE $=M$ & & \multicolumn{3}{c}{$P_{b u s, d}$} \\
\cline { 3 - 5 } & & $L T$ & $M T$ & $H$ \\
\hline SOC & $L$ & $L$ & $L C$ & $M$ \\
& $M$ & $L$ & $L C$ & $M$ \\
& $H$ & $L$ & $L C$ & $M$ \\
\hline SOE $=H$ & & & $P_{b u s, d}$ & \\
& & $L T$ & $M T$ & $H$ \\
\hline SOC & $L$ & $M$ & $M$ & $L$ \\
& $M$ & $M$ & $M$ & $L$ \\
& $H$ & $M$ & $M$ & $L$ \\
\hline
\end{tabular}

Based on actual engineering experience and the analysis in the literature[1,8,13 ], taking the structure of the hybrid system and working mode into consideration, The design of FLC1 fuzzy control rules follows the following principles: 1) when the train at high demand, high power and SOC or SOE, power battery or 
super capacitor discharge with grid power supply, the area has a small net at one in the hybrid system increase a work mode, in order to reduce the peak current of grid side; 2) when the train needs high power, avoid charging the power battery or the ultracapacitor with high current; 3) under braking conditions, the power grid within the grid does not charge the power battery or the supercapacitor through the dc bus.

According to the above analysis, the FLC2 fuzzy inference rules are shown in table 2 and table 3, table 2 is $P_{\text {batt,d }}$ 's fuzzy inference rules, table 3 is $P_{\text {uc,d }}$ 's fuzzy inference rules. The fuzzy inference form of FLC2 is: "If $P_{\mathrm{uc}, \mathrm{d}}$ for $\mathrm{Ai}$ and $\mathrm{SOC}$ for $\mathrm{Bi}$ and $\mathrm{SOE}$ for $\mathrm{Ci}$, then $P_{\mathrm{batt}, \mathrm{d}}$ for $\mathrm{Di}, P_{\mathrm{uc}, \mathrm{d}}$ for $\mathrm{Ei}$ ".

\section{Simulation Calculation}

ADVISOR software adopts the hybrid power system modeling method of "backward simulation as the main method, and forward simulation as the auxiliary method" [15], which has high simulation speed and accuracy. Based on this modeling method, this paper established the simulation sysitem of hybrid electric tram in MATLAB/Simulink environment [16], and showed the top block diagram of the simulation system figure 5 . In figure 5, according to the direction of backward simulation, that is, starting from the reverse of energy flow, there are working condition model, train model, wheel/axle model, transmission system model, motor model, electrical load model, dc bus model, energy management strategy, ESS model and power grid model.

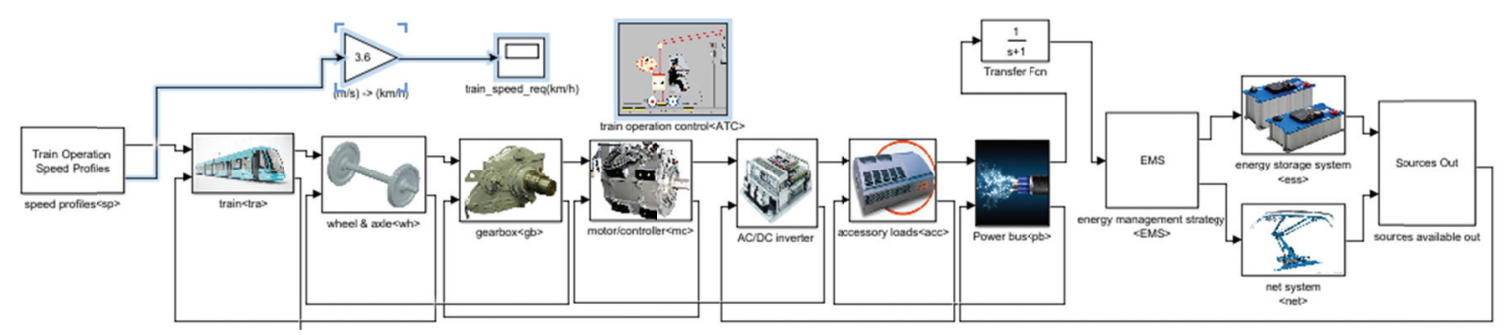

Figure 5. The simulation system of hybrid tramway based on MATLAB/simulink

\subsection{Simulation Parameters}

To verify the feasibility of the energy management strategy proposed in this paper, the first 6 sections and 7 platforms of a planned line in China are taken as the simulation lines for simulation analysis in the hybrid electric tram simulation system shown in figure 5.

The main simulation parameters of the train are shown in table 4 . The total length of the simulation section is about $15.6 \mathrm{~km}$. The length of each platform is $64 \mathrm{~m}$ and the stopping tinne is $30 \mathrm{~s} .32 \mathrm{~m}, 805 \mathrm{~m}$, $1231 \mathrm{~m}, 1796 \mathrm{~m}, 2249 \mathrm{~m}, 2948 \mathrm{~m}, 3638 \mathrm{~m}, 4110 \mathrm{~m}, 5053 \mathrm{~m}, 5515 \mathrm{~m}, 6217 \mathrm{~m}, 7014 \mathrm{~m}, 7870,8966 \mathrm{~m}, 10215 \mathrm{~m}$, $10970 \mathrm{~m}, 11687 \mathrm{~m}, 12424 \mathrm{~m}, 13450 \mathrm{~m}, 14067 \mathrm{~m}, 15226 \mathrm{~m}, 15658 \mathrm{~m}$; The maximum gradient is $14 \%$, and the minimum turning radius is $35 \mathrm{~m}$; Set up a power grid inside the platform.

Table 4. The main parameters of train

\begin{tabular}{ll|ll}
\hline Parameter name & Parameter value & Parameter name & Parameter value \\
\hline Train weights $/ \mathrm{t}$ & 80 & Maximum operating speed & 4 \\
Gearbox drive & 6.28 & Maximum acceleration & 1 \\
Inertial mass & 0.09 & Maximum deceleration & 1 \\
Basic resistance & 1.59 & DC - DC efficiency/\% & 9 \\
Basic resistance & 0.00921 & Motor rating & 5 \\
Basic resistance & 0.00026 & Quantity of motor & 1 \\
\hline
\end{tabular}

MAXWELL BCAP3000 P270 is selected as the system's super capacitor monomer, while a certain type of lithium ion battery with a rated capacity of $40 \mathrm{Ah}$ and a rated voltage of $3.2 \mathrm{v}$ is selected as the power battery monomer, of which the capacity is expanded into the super capacitor group and power battery 
group as shown in table 5 . The whole vehicle is equipped with three sets of power systems, and the main parameters of each set of ESS are shown in table 5.

Table 5. The main parameters of ESS

\begin{tabular}{lcll}
\hline \multicolumn{4}{c}{ Ultracapacitor group parameters } \\
\hline Rated voltage/V & 48 & Nominal capacity/F & 49 \\
Maximum discharge current/A & 20 & Maximum charging current & 20 \\
Discharge SOE cut-off value & 30 & Charging SOE cut-off value & 10 \\
\hline \multicolumn{4}{c}{ Power battery } \\
\hline \multicolumn{4}{c}{ parameters } \\
\hline Rated voltage/V & 48 & Nominal capacity/Ah & 12 \\
Discharge rate/C & 3 & Charging ratio/C & 1 \\
Discharge SOE cut-off & 30 & Charging SOE cut-off & 10 \\
\hline
\end{tabular}

\section{$5 \quad$ Results}

Based on the simulation environment and vehicle configuration parameters, the dynamic performance and economy of the train are simulated. To compare the advantages and disadvantages of the DFLC energy management strategy proposed in this paper, it is compared and analyzed with the rule-based switching energy management strategy $(\mathrm{RBC})$ proposed in literature $[7,16]$. Simulation results are shown in figure 7 , figure 7 , figure 8 and table 6 . Among them, figure 7 is the train running speed curve based on the two energy management strategies, figure 8 is the power output curve of each power source in the train running, figure 8 is the ESS charge-state curve in the train running, and table 6 is the main comparative simulation data of the two energy management strategies. Where, the energy recovery rate in table 6 is defined as

$$
\eta_{\text {recy }}=\frac{E_{\text {recy,tot }}}{E_{\text {wh,br }}} 100 \%
$$

where, $E_{\text {recy,tot }}$ is the total energy recovered by energy storage equipment $(\mathrm{kWh}) ; E_{\text {wh,br }}$ is the total braking energy (kWh) at the wheel end when braking.

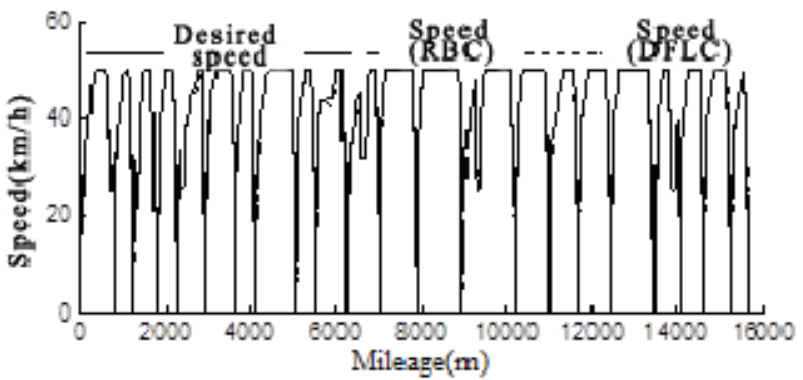

Figure 6. Speed curves of tramway

It can be seen from figure 7 and figure 8 that the train speed based on the two energy management strategies of DFLC and RBC can track the desired speed, both of which meet the requirements of the train's dynamic performance. The power grid, power battery and ultracapacitor work together to meet the power requirements of the working condition. 

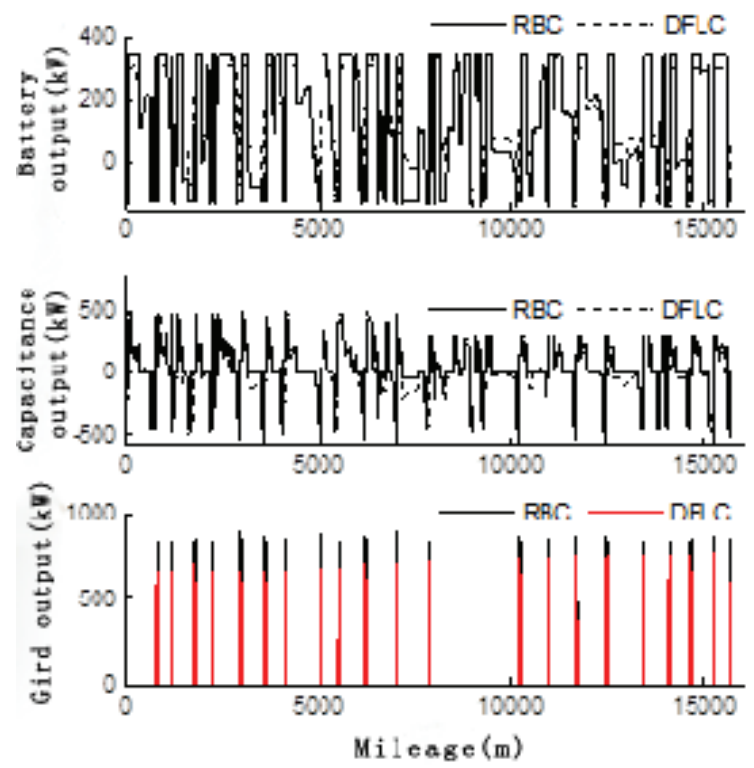

Figure 7. Output power curves of hybrid system
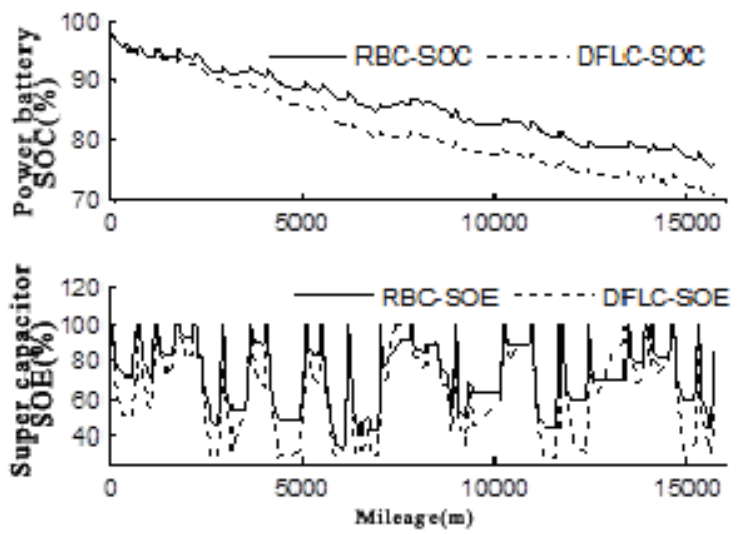

Figure 8. The comparisons between energy management strategy based on DFLC and RBC

Table 6. The comparisons between energy management strategy based on DFLC and RBC

\begin{tabular}{lll}
\hline Content & RBC & DFLC \\
\hline Average train speed/(km/h) & 35.73 & 35.68 \\
Train running time/s & 2207 & 2209 \\
Power grid traction energy consumption/kWh & 29.3 & 25.7 \\
Power cell energy consumption/ kWh & 63.0 & 56.8 \\
Ultracapacitor energy consumption/ kWh & 26.0 & 38.5 \\
Power batteries recycle energy/ kWh & 11.7 & 6.3 \\
Ultracapacitors recover energy/ kWh & 20.2 & 32.2 \\
Final SOC value of power battery/\% & 75.4 & 71.2 \\
Total traction energy consumption/ kWh & 118.3 & 121.0 \\
Energy recovery/\% & 42.3 & 51.6 \\
\hline
\end{tabular}

Compared with RBC-based energy management strategy, under DFLC-based energy management strategy: the power grid will charge ESS when the power supply starts in the grid area and the power grid stops or at the moment of low power traction. At the moment of high-power traction, the power output of 
energy storage equipment reduces the power output of the power grid. In the netless area, the time of the ultracapacitor and the power battery work together is increased, which reduces the time that the power battery works with a large current. At the same time, before the train braking, the SOE of the ultracapacitor is lower and more regenerative braking energy is recovered. Therefore, the energy management strategy based on DFLC proposed in this paper is effective.

It can be seen from figure $7 \sim$ figure 8 and table 6 that, compared with the energy management strategy based on RBC, the energy management strategy based on DFLC can reduce the average running speed of trains by about $0.05 \mathrm{~km} / \mathrm{h}$, increase the running time by about $2 \mathrm{~s}$, and reduce the dynamic performance, which it can be almost ignored in the actual operation. The power grid traction energy consumption decreased by about $12.3 \%$, the total amount of regenerative braking energy recovered by ESS increased by about $20.4 \%$, the energy recovery increased by about $9.3 \%$, and the total energy consumption of traction increased by about $2.3 \%$. Therefore, more regenerative braking energy is recovered when the dynamic performance decreases less, and the energy utilization efficiency is greatly improved.

\section{Discussion}

The results of calculation and simulation experiments show that energy management strategy based on DFLC can keep the final values of SOC and supercapacitor SOE of power battery low. This is because the DFLC energy management strategy reduces the high current charge in the case of high SOC/SOE in the braking section or in the power grid range. As expected, the effectiveness and performance of the energy management strategy based on DFLC were verified. Furthermore, under the cut-off condition, energy management strategy based on DFLC enlarges the ESS workspace, especially supercapacitors. This strategy suppresses the high power output of power batteries and power grids and reclaims more regenerative braking energy.

\section{Conclusion}

In this paper, a class of hybrid vehicle energy storage type trolley power system structure, work mode is analyzed, a network and mesh free interval fuzzy controller is respectively designed. Furthermore, this paper proposes a power management strategy based on double fuzzy control, and based on the MATLAB/Simulink simulation analysis was made on hybrid simulation system of tram. The results indicate that the proposed EMS based on double fuzzy logic control can guarantee the reliable operation of the hybrid system during the real drive cycle, and recycling more regenerative braking energy, which will provide an importance guiding role for the design of energy management system for the hybrid tramway.

Acknowledgements. The project was funded by the Southwest Minzu University Graduate Innovative Research Project (Master program CX2018sz97).

\section{References}

1. Hong Z, Li Q, Han Y, et al. An energy management strategy based on dynamic power factor for fuel cell/battery hybrid locomotive[J]. International Journal of Hydrogen Energy, 2018, 43(6):3261-3272.

2. Kotra S, Mishra M K. Design and Stability Analysis of DC Microgrid with Hybrid Energy Storage System[J]. IEEE Transactions on Sustainable Energy, 2019, PP(99):1-1.

3. Hannan M A, Hoque M M, Hussain A, et al. State-of-the-Art and Energy Management System of Lithium-Ion Batteries in Electric Vehicle Applications: Issues and Recommendations[J]. IEEE Access, 2018, 6(1):19362-19378.

4. CHEN Weirong, ZHANG Guorui, MENG Xiang, et al. Dynamic performance analysis and design of fuel cell hybrid locomotive[J]. Journal of Southwest Jiaotong University, 2017, 52(1): 1-8.

5. Venkata S V G, Madichetty S. Application of superconducting magnetic energy storage in electrical power and energy systems: a review[J]. International Journal of Energy Research, 2018, 42(2).

6. Kouchachvili L, Yaïci W, Entchev E. Hybrid battery/supercapacitor energy storage system for the electric vehicles[J]. Journal of Power Sources, 2018, 374:237-248.

7. YANG Jibin, ZHANG Jiye, SONG Pengyun, et al. Research on the Control Strategy of Power System for Hybrid Electric Train [J]. Journal of Southwest Jiaotong University, 2015, 50(1): 20-26. 
8. Veerapaneni S, Palaniappan K, Cuzner R M. Analysis of solar and battery requirements for hybrid DC/AC powered households in the USA[J]. Energy Efficiency, 2019:1-19.

9. Carignano, Mauro, Roda, Vicente, Costa-Castello, Ramon, et al. Assessment of energy management in a fuel cell/battery hybrid vehicle[J]. IEEE Access, 2019, 7:16110-16122.

10. Wei C, Fei L, Hua Z, et al. Development of dynamic energy benchmark for mass production in machining systems for energy management and energy-efficiency improvement[J]. Applied Energy, 2017, 202:715-725.

11. He T, Xu W, Lu Z, et al. Adaptive Fuzzy Logic Energy Management Strategy Based on Reasonable SOC Reference Curve for Online Control of Plug-in Hybrid Electric City Bus[J]. IEEE Transactions on Intelligent Transportation Systems, 2018, PP(99):1-11.

12. YANG Jibin, SONG Pengyun, ZHANG Jiye, et al. Research on simulation system of hybrid modern tramway[J]. Journal of Mechanical Engineering, 2017, 53(18): 161-168.

13. HUANG Wenqiang, LI Qi, CHEN Weirong, et al. Fuel Cell Tram Regenerative Braking Energy Recovery Method Based on PMP Energy Management Strategy and Braking Speed Optimization Strategy [J]. Proceedings of the CSEE, 2019.

14. WU Jie, WANG Qingyuan, DU Xin, et al. Modeling and energy management strategy of hybrid train[J]. Computer Simulation, 2016,33(1):161-165,238.

15. HERRERA V I, GAZTANAGA H, MILO A, et al. Optimal Energy Management and Sizing of a Battery-Supercapacitor-Based Light Rail Vehicle With a Multiobjective Approach[J]. IEEE Transactions on Industry Applications, 2016, 52(4):3367-3377.

16. Jian C, Xu C, Wu C, et al. Adaptive Fuzzy Logic Control of Fuel-Cell-Battery Hybrid Systems for Electric Vehicles[J]. IEEE Transactions on Industrial Informatics, 2018, 14(1):292-300.

17. YANG Jibin, SONG Pengyun, ZHANG Jiye, et al. Research on simulation system of hybrid modern tramway[J]. Journal of Mechanical Engineering, 2017, 53(18): 161-168. 